\title{
Incentives and uncertainty: an empirical analysis of the impact of demand on innovation
}

\author{
Roberto Fontana* and Marco Guerzoni** \\ * University of Pavia and CESPRI - Bocconi University, Italy \\ ** Schiller Universität, Germany
}

This Draft: August 2007

* Corresponding author: Department of Economics, University of Pavia, Via San Felice 5, 27100, Pavia; and CESPRI, Bocconi University, Via Sarfatti 25, 20136, Milan, Italy; Tel. +390258363037; Fax. +390258363399; e-mail: roberto.fontana@unibocconi.it

Corresponding author's address: CESPRI, Bocconi University, Via Sarfatti 25, 20136, Milan, Italy;

** Schiller Universität, c/o Lehrstuhl für Microökonomik (Prof. Dokt. Cantner), Carl-Zeiß-Straße 3, 07743 Jena. Germany. Phone: +493641943275; email: marco.guerzoni@wiwi.uni-jena.de 


\section{ABSTRACT}

We study the impact of demand on innovation. By focussing on a sample of SMEs in several industries and European countries, we analyse how demand stimulates innovation both by providing economic incentives and by reducing uncertainty. Considering the size of the market as a proxy for the presence of demand, we find support for the idea that the presence of incentives stimulates innovation. This is particularly true for process innovation. Considering interaction with customers as a way to reduce uncertainty, we find that firms with a high propensity to interact with external actors are more innovative and they tend to introduce product innovations. Firm size, R\&D expenditures and sectoral effects also matters.

JEL codes: O31, O33;

Key words: Demand, Product innovation, Process innovation;

EAEPE RA code: D 


\section{Introduction}

An extensive literature on the issue of the influence of demand upon innovation exists.

According to this literature, demand can influence firms' innovative choices in two ways. On the one hand, there is the 'incentive effect' according to which, once an innovation is introduced in the market, demand acts as a multiplier on the increased firm mark-up. As suggested by Schmookler (1962), the impact of this effect is stronger the larger is the market and it favours process innovations. On the other hand, there is an 'uncertainty effect'. This effect impinges upon the assumption that introducing new or radical products is difficult and forecasting their pace of adoption hard, due to the intrinsic uncertainty associated to novelty. Within this context demand can pull innovation by 'channelling' to firms useful knowledge about markets' need. By reducing firms' uncertainty about expected profits, knowledge can stimulate innovation. This effect was first highlighted by Myer and Marquis (1969) and it has been further studied by von Hippel (1978) and, more recently, by other scholars (Herstatt and Von Hippel, 1992; Morrison et al., 2000). Despite the presence of a rich literature aiming at studying these effects, most of the existing contributions tend to find limited empirical support for their existence. Indeed, their presence has been strongly questioned (see among others Kleiknecht and Verspagen, 1990; Mowery and Rosenberg, 1978) on the ground that the conceptualization of demand is not clear, the mechanism at work is not always specified, and the causality flow is often spurious.

In this paper we suggest that the paucity of empirical support may derive from two reasons. First, it can be argued that a clear-cut distinction between the two effects is hard to observe. Both effects might be at work conjunctly and they might be difficult to disentangle. Second, it should be acknowledged that these effects impinge upon firms' choices in a different way and an empirical test should consequently take this into account. We present an empirical analysis of the influence of demand on product and process innovations, which attempts to differentiate between these two effects. In particular, we study their joint impact on firms' propensity to innovate on a cross-section of innovative firms in Europe. Data come from a survey of small and medium-sized enterprises (SMEs). The survey was carried out in 2000 and covers seven EU countries (Denmark, France, Germany, Greece, Italy, the Netherlands and the UK) and five sectors: food and beverages, chemicals (excluding pharmaceuticals), communications equipment, telecommunications services and computer services (Caloghirou et al., 2006). 
We first analyze the existing literature on the issue of the relationship between demand and innovation and discuss its achievements and main limits. Second we discuss the information collected in the survey that are relevant to the understanding of the relationship between demand and innovation. Finally, we use an econometric model to account for the influence of economic incentives and uncertainty on both firms' propensity to innovate and the direction of their innovative efforts. The analysis of the joint effect of these mechanisms is the first original contribution of the paper. Moreover, it has to be noted that these demand related effects might not impact homogeneously across firms. By controlling for sectoral level specificities and firm level heterogeneity our analysis will be able to suggest what micro characteristics are relevant to asses the impact of both effects on the propensity to innovate.

The paper is organised as follows. Next section provides the necessary literature background and introduces the main hypotheses. Section 3 will present the data and the main findings. Section 4 concludes.

\section{Background literature and hypotheses}

The analysis of the influence of demand upon innovation dates back to the 1960s, when Schmookler (1962; 1966) and Myers and Marquis (1969) highlighted the excessive emphasis given to technology as a major source of innovation:

"New goods and new techniques are unlikely to appear, and to enter the life of society without a pre-existing - albeit possibly only latent-demand" (Schmookler 1962: 1).

Both Schmookler and Myers and Marquis focussed on the role of demand, but they addressed the issue from different perspectives. Schmookler considered demand as a source of economic incentive to invention. He argued that, being invention an economic activity, its evolution should be driven by expected profitability. In particular, if an improvement in the production techniques or in the product's quality ensured a higher mark-up per unit, the value of the future stream of profits would be the higher the greater the number of units sold. Considering 
the size of the market as a proxy for the expected demand, incentives to innovate should be positively correlated with the size of the market.

Analytically, consider the binary variable $y_{t}$, taking value 1 if a firm is innovating and 0 if it is not, and assume that the probability $P_{t}$ of a firm being innovative at time $t$ depends on an information set $\Omega_{t}$ :

$$
P_{t} \equiv \operatorname{Pr}\left(y_{t}=1 \mid \Omega_{t}\right)=E\left(y_{t} \mid \Omega_{t}\right)
$$

Schmookler assumed that the relevant information set to predict $y_{t}$ consists of the incentives generated by the expected profit $\square_{t}$. Thus,

$$
P_{t} \equiv E\left(y_{t \mid} \mid \Omega_{t}\right)=F\left(\Pi_{t}\right)
$$

where $F$ is a transformation function defining a CDF of a probability distribution. ${ }^{1}$ At a given point in time, profit for the firm $i$ can be then written as:

$$
\Pi_{i}=(p-c) x_{i}-E
$$

where $p$ is the price of a product, $c$ its marginal cost of production, $x_{i}$ the quantity sold by the firm and $E$ the fixed costs of invention. If $S$ is the total expenditure in a sector, the firm's market share $s$ can be defined as:

$$
s_{i}=\frac{p x_{i}}{S}
$$

and equation (3) then becomes

$$
\Pi_{i}=\left(k s_{i}\right) S-E_{i}, \text { with } k=\left(1-\frac{c}{p}\right)
$$

and, ceteris paribus: 


$$
P_{t} \equiv E\left(y_{t} \mid \Omega_{t}\right)=F\left(S_{t}\right)
$$

Thus, for a firm the larger is the market size $S$, the larger are its expected profits, as well as the incentives and the likelihood to innovate.

It is clear that this line of reasoning holds only under two assumptions. First, an innovation should have no effect either on the total market expenditure, or on a firm's market share. Second, the fixed costs of invention should be uniformly spread across firms. These implicit assumptions have been highlighted in the literature. Scherer (1982) in particular, re-ran Schmookler's analysis and found lower coefficients for the significant demand related variables. This result was not surprising given that the expected size of the market did not always completely overlap with the demand faced by firm. Indeed, in his analysis Schmookler referred mainly to established industries with an oligopolistic structure of the market and to innovation in existing products (Schmookler, 1966: 153), because in this case, the size of actual market is a good proxy for the expected sales. Scherer, on the contrary, used a broader data-set and included industry where innovation could either modify the market structure by providing a temporary monopoly or reduce profits by cannibalizing existing products. Indeed, a model, which aims at taking into account the effect of market size upon innovation, should consider the structure of the market as endogenous. Analytical models of patent race (Reinganum, 1983) and of endogenous market structure (Sutton, 1998) have followed this path. Similarly, Kleinknecht and Verspagen (1990) revisited Schmookler dataset and highlighted the presence of reverse causality. If, on the one hand, the size of the market sets incentives to invention, it is also true that, on the other hand, an innovation has positive effect on the size of the market itself. All in all, this discussion suggests that Schmookler idea can be robust, especially in those sectors where competition is relatively high, process innovations or incremental product improvements play the major role, and the size of the market is likely to remain stable. Indeed, recent empirical research has been focusing on single sectors for which controlling for both market structure and reverse causality is easier. For instance, Lichtenberg and Waldfogel (2003) addressed the problem of incentives of pharmaceutical firms in investing in R\&D to cure rare diseases, and Popp (2002) explored the correlation between patents and energy prices in selected industries. 
Besides acknowledging the role of demand as a provider of economic incentives for innovation, Myers and Marquis (1969), Langrish et al., (1972) and other empirical studies (Ienson, 1969; National Science Foundation, 1959; Rothwell and Freeman, 1972; Freeman, 1968; Berger, 1975; Boyden, 1976; Lionetta, 1977) stressed the crucial role of demand as a direct source of innovation. These works tried to understand, through questionnaires and interviews, the technical and economic context in which innovations occur. They found that in most cases demand was perceived by the innovative firms as the leading factor of a successful innovation, in the sense that customers provided firms with knowledge such as new ideas or specific requirements.

For this stream of literature, the probability of firms being innovative can be summarized as:

$$
P_{t} \equiv E\left(y_{t \mid} \mid \Omega_{t}\right)=F\left(I_{t}\right)
$$

where the variable $I$ is a proxy capturing firms' information on user needs. More and better information reduces uncertainty and increases the probability for the firm to introduce a successful innovation. The main weakness of this approach was the identification and the meaning of the variable $I$ which, at least initially, had remained blurred. This is the point made by Mowery and Rosenberg (1978) and Dosi (1982), who argued that the concept of demand itself as used by Myer and Marquis was too broad, vague and difficult to operationalise. According to Dosi:

"[...] to conclude that it is demand that drives innovation, market must clearly be distinguished from the potentially limitless set of human needs" (Dosi, 1982: 150, bold added).

Failure to do this would lead to the:

"[...] incapability of defining the why and when of certain technological developments instead of others and of a certain timing instead of other" (ibid.). 
Von Hippel was the first author to respond to these criticisms by introducing the concept of 'lead users' defined as “consumers whose present strong needs will become general in a marketplace months or years in the future” (von Hippel, 1986: 792). Since they are knowledgeable about how to benefit significantly by the solution to a problem, lead users are both able and willing to interact with firms, and become important sources of information. On the same line, Teubal (1979) suggests that the influence of demand upon innovation depends on "need determinateness, the extent to which preferences are specified (or need satisfaction is expressed) in terms of product classes, functions and features" (Teubal, 1979, quoted in Clark, 1985: 244). Recently, von Tunzelmann et al. (2003) introduced the concept of user capabilities (i.e. the ability of reaping utility from an innovation). This ability depends on users' capabilities in coupling their needs with the solution provided by the innovation (i.e. sophistication). Similarly Malerba et al. (2003) and Adner and Levinthal, (2001) focused on the role of heterogeneity in customers' preferences as a source of innovation.

The concept of sophistication overcomes the Mowery-Rosenberg-Dosi critique because demand is no longer considered as the "potentially limitless set of human needs" but as a set of specific needs put forward by sophisticated users. As a consequence, Dosi's argument is 'turned upside down' and demand becomes the source of information necessary to select the opportunities that actually fit with users' preferences within the potentially limitless set of technological opportunity. In this case, the variable $I$ is no longer conceived as a vague idea of demand, but as a proxy for those concrete interactions that really take place between a firm and the sophisticated users (both customers and firms) it is producing for. As put forward by von Hippel (1982), the role of users is mostly successful either when they propose ideas for new product or even when they create prototypes.

In the light of the above discussion, we can point to two different mechanisms underlying the way demand acts upon innovation. On the one hand, demand is conceived as an incentive mechanism'. As suggested above, this should hold especially for process innovation or incremental product innovation where it is easy to forecast the expected size of the market. On the other hand, introducing either new products or radical product improvements and forecasting their pace of adoption is a difficult task due to the intrinsic uncertainty associated to novelty. According to this view, demand can trigger innovation by reducing uncertainty (i.e. by providing useful knowledge about market needs). In other words, by reducing uncertainty about expected profits, knowledge can stimulate innovation. 
It is straightforward that information about users' requirements is relatively more necessary for developing product than for process innovations, which tend instead to impinge more upon firms' technological knowledge base. Thus, not only there are two different demand-led mechanisms at work, but also each of them leads to a different type of innovative output.

While the presence of these two effects has long been discussed, the different impact on the innovative output has rarely been empirically disentangled. This might be one of the reasons why after five decades the debate on the relationships between demand and innovation is still on the research agenda. Our following analysis empirically addresses the dualism contained both in the underlying mechanism of the demand-pull hypothesis and in the resulting outcomes. In the rest of the paper we tackle two issues. First, we test the presence of the two effects without differentiating between process and product innovations, as it has been previously done in the literature. Second, we provide evidence for the presence of difference innovative output due to the alternative mechanisms underlying these effects.

To undertake the first task, we consider

$$
P_{t} \equiv E\left(y_{t \mid} \mid \Omega_{t}\right)=F\left(S_{t}, I_{t}\right)
$$

and test:

Hypothesis \# 1: Schmookler Hypothesis. The size of the market $(S)$ has a positive impact on the probability of firm being innovative;

Hypothesis \# 2: Myer and Marquis Hypothesis. The degree of interaction with users (I) has a positive impact on the probability of firm being innovative.

Although we control for firms and sector heterogeneity in order to take into account the criticisms suggested in the existing literature, we do not expect to find a clear result in term of coefficients' significance. Indeed, the way in which the hypotheses are formulated does not account for the different mechanisms underlying the two effects. The size of the market rarely has a positive impact on the probability of introducing new products. Moreover, there might 
not be a specific reason why interactions with external partners (i.e. customers in particular) should help firms to develop cost reducing process innovation.

To undertake the second task, we note that innovative processes are complex and both incentive and uncertainty effects are very likely to play a role at the same time. Thus, it is problematic to neatly disentangle a 'pure' incentive effect from a 'pure' uncertainty effect. However, if both effects are present, we should observe, in innovative firms, a relatively higher propensity toward carrying out process innovation when the market size increases and a relatively higher propensity towards carrying out product innovation when the interaction with users increases.

Analytically speaking, we are interested in observing the realization of a new variable $\bar{y}$ with value 0 if a firm pursues both process and product innovation, 1 if it focuses on product innovation and 2 when it focuses on process innovation:

$$
P_{t} \equiv E\left(\bar{y} \mid \Omega_{t}\right)=F\left(S_{t}, I_{t}\right)
$$

Now, contrasting innovative choices, we should observe that a marginal increase in interaction with users has a positive impact on the likelihood of observing product innovations, while a marginal increase in market size positively affects the likelihood of undertaking process innovations.

Thus we test:

Hypothesis \# 3: Incentive effect. The size of the market stimulates innovative firms more towards process than product innovation.

Hypothesis \# 4: Uncertainty effect. The degree of interaction with users stimulates innovative firms more towards product than process innovation.

In the remaining sections of the paper we will address each hypothesis in turn. If findings reject these hypotheses, we can conclude that, at least in the perception of firms in our 
sample, demand plays a minor role in innovation. If not, we should find some support either for our hypotheses or, at least, for some of them. ${ }^{2}$

\section{Empirical analysis}

We carry out the analysis on a cross-section of data from Small and Medium Size Enterprises (SMEs) in seven EU countries (Denmark, France, Germany, Greece, Italy, The Netherlands and the UK) and five industries: Food and beverages (NACE 15), Chemical excluding Pharmaceuticals (NACE 24 minus NACE 24.4), Communication Equipment (NACE 32), Telecommunications Service (NACE 64.2) and Computer Services (NACE 72). This information comes from a survey carried out in 2000, which targeted SMEs, whose size ranged between 10 and 1,000 employees. ${ }^{3}$ The survey is the European equivalent of the ‘Carnegie Mellon Survey’ on industrial R\&D in US manufatcuring sector (described in Cohen et al., 2002), and it was aimed at investigating the extent, implications and mechanisms of innovation-related knowledge flow in the European industry. The questionnaire was divided in two parts. In the first part questions were aimed at gleaning general information on the respondents (i.e. innovativeness, collaborations with external partners, sources of information for innovative activity etc.). In the second part, respondents were asked to identify the "most economically important innovation introduced by the firm in the most recent three years" and to answer questions related to this innovation including information on the most important external contributors to the innovation.

The survey collected 675 valid responses. Of the respondent firms, 558 turned out to be innovators and 518 were able to identify their most economically important innovation. Those who identified the most important innovation constitute our sample. 355 firms were 'particularly innovative' (i.e. they did both product and process innovation). On average these firms introduced $16 \%$ of their new improved product and/or processes in collaboration with external partners (i.e. by relying on external informations). To shed some preliminary light on the relationship between innovativeness and the extent of reliance on external collaboration, we split the sample of those who collaborate in two: firms that relied more than average on external partners (168 or $47 \%$ of the sample) and firms that did not. Data suggest that innovative firms in the Food and Beverages (28\%) and in the Computing Services (27\%) sectors generally rely more than average on external partnerships for innovation. Firms in the Communication Equipment (15\%) and Telecommunication Services (10\%) sector display the lowest frequencies and Chemical firms (20\%) are in the middle. 
To explore the relationship between innovativeness and demand, we look at the role of external sources of information on innovative firms. Of the 518 firms who identified their most important economic invention, 233 firms (or 45\%) stated that customer interaction was the most important source of information for both innovation ideas and completion thus suggesting that interacting with customers is important for innovation. The importance of customer interaction varies across sectors though. While for about one quarter of innovative firms in Computer Services, Chemicals and Food and Beverages customer interaction is the most important source of innovation, percentages are considerably lower for firms in Telecommunication Services and Communication Equipment sector (10\% and 16\% of respondents respectively).

A further break down of these data by type of innovation is depicted in Figure I. Indeed 210 firms refereed to their most important innovation as 'product innovation', 85 identified it as 'process innovation' and 223 as 'combined product /process or service innovation'. What is suggested by the distribution of responses is the relatively higher relevance of customer interaction for firms that carried out 'combined product /process or service innovation' across all sectors but Telecommunication Services, compared to the other types of innovation. Among those sectors whose most important innovation was a 'product innovation', Communication Equipment and Computer Services rely more than any other on customers interaction followed by Chemical firms. As expected, firms whose most important innovation was a 'process innovation' have a lower distribution of responses. Among these firms, Food and Beverages are those who relied more on customer interaction.

[Figure I about here]

Finally we consider the relationship between market size and type of innovation. One questions asked firms to report the number of competitors in their main business which can be considered to be a proxy of the size of their market. 486 firms answered this question. 119 (24\%) faced between 0 and 4 competitors and were included into the Small Market Size category; 109 (23\%) faced between 5 and 9 competitors and were assigned to the MediumSmall Market Size category; 130 (27\%) faced between 10 and 15 competitors and were included in the Medium-Large Market Size category, and 128 (26\%) with more than 15 competitors were included into the Large Market Size category. Figure II depicts the 
percentages of respondents who identified their most important innovation by market size and type of innovation. Results indicate that a relatively large share (30.65\%) of firms operating in medium-large markets tend to do product innovation. Firms doing 'combined product /process or service innovation' are more evenly distributed across market sizes though the largest share of firms doing combined product /process or service innovation operates in large markets. Particularly interesting for the purpose of our paper is the case of process innovation. In this case, percentages suggest that the majority (57\%) of firms that do 'process innovation' operate in large and medium-large markets.

[Figure II about here]

Again there is heterogeneity across sectors. In Figure III we plot the percentages of respondents who identified their most important innovation as 'process' innovation by market size and sector of activity. While the majority of Chemical and Communication Equipment firms doing process innovation operate in large markets, firms delivering services (both in the Computer and the Telecommunication sector) operate in medium-large markets. Interesting is the case of the Food and Beverages sector that witnesses a majority $(43.75 \%)$ that operates in small markets.

[Figure III about here]

All in all, these descriptive statistics seem to corroborate our hypotheses. More innovative firms generally tend to interact more with external partners which are a source of external information. Interacting with customers is particularly important for firms doing product innovation. Market size positively influences innovation and this is particularly true for firms doing process innovation. On the basis of this preliminary evidence, we proceed by carrying out two types of analysis. First, we investigate the determinants of the innovative activity by focussing on firms who performed both process and product innovation. This analysis is intended to shed light on Hypotheses 1 and 2. Second, we focus on the most important innovation alone and study the determinants of product innovation when contrasted with process or other types of innovation. This analysis will provide evidence on the role of both uncertainty and incentives underlying innovation and is aimed at supporting or disproving Hypotheses 3 and 4. 


\subsection{Explanatory variables}

Our explanatory variables include indicators for the size of the market, interaction with customers as well as a set of controls for firm size and industry related dummies. Concerning market size, our discussion in Section 2 has stressed how it may provide incentives for innovation. Indeed, central to the Schmookler argument is the role of innovation as a driving force underlying the increase in price margin induced by a decrease in production cost especially in the case of process innovation. To the extent to what price margin is positively linked to market power, related indicators such as firms' market shares have been used in the literature. Indeed, Link (1982) finds that among more R\&D intensive industries, the share of $\mathrm{R} \& \mathrm{D}$ dedicated to process innovation increases with market concentration. It has to be noted that, in specific contexts, the use of market shares as a proxy for market size may be questionable. Brouwer and Kleinknecht (1996) for instance have reservations about the use of domestic market shares in the case of open economies characterised by the presence of small firms. As an alternative they use the share of SMEs in a sector number of firms as an indicator of the intensity of competition. Given that our sample is mainly constituted by SMEs, we follow their approach and consider the number of firms competing in the same market as a sensible proxy for the size of the market. MKT SIZE is the log of the number of competitors in the main business as stated by respondents. We expect this variable to impact positively on innovation tout-court (Hypothesis 1) and on the likelihood of doing process innovation (Hypothesis 3) when compared to product innovation.

Concerning demand as a source of knowledge for new ideas and/or specific requirements, a bourgeoning literature exists on the role of interactions with external partners as well as on the importance of external channels of information as sources of ideas for innovation (Laursen and Salter, 2006). We exploit the richness of the KNOW survey to develop two different indicators that can be used to properly test our research hypotheses. In particular, in the first part of the questionnaire firms were asked to state what percentage of new or improved production processes or products was introduced in collaboration with external partners. ${ }^{4}$ EXT INTER is the simple mean of the percentage of both improved products and processes introduced in collaboration with external partners. External interaction is crucial for attracting new ideas. To the extent to what demand entails interaction and external partners are a major component of demand, it seems sensible to choose this variable to test Hypothesis 2. It has to be noted however, that 'external partners' include but are not limited to users. Thus this variable may actually overstate the impact of interaction with users on innovation. 
In the second part of the questionnaire, which focuses on the most economically important innovation, firms were asked to select the most important contributor for both innovation completion and innovation idea within a list of possible candidates (Competitors, Suppliers, Customers, Universities and PROs, Consultants). CUST INTER is a dummy equal to 1 for firms who selected customers as the most important contributors for either innovation idea or completion and 0 otherwise. This is an indicator of user involvement in the innovative process which will be used to test Hypothesis 4.

Following Czarnitzki and Kraft (2004), who also worked on the KNOW dataset, we construct the following controls. First, we consider whether the firm perform R\&D activity. R\&D is a dummy equal to 1 if the firm performs R\&D activity continuously and 0 if not. ${ }^{5}$ The positive link between R\&D activity and innovativeness at firm level has been vastly studied. Empirical evidence in support of this positive relationship has been found and explained in terms of the expertise necessary to identify and apply relevant external knowledge i.e. 'absorptive capacity' (Cohen and Levinthal, 1990). Consistently with these findings we expect firms that perform R\&D activity continuously to be more likely to carry out both product and process innovation. Second, we account for firm size. Again, several contributions exist in support of the influence of firm size on innovativeness. Freeman and Soete (1997) find that larger firms are mainly responsible for process innovation in Chemical firms in the late $19^{\text {th }}$ and $20^{\text {th }}$ centuries. Pavitt et al. (1987) find that for larger firms generally the share of innovative effort devoted to process innovation is greater. More recent analyses mainly point to the presence of a positive relationship between firm size and the composition of $\mathrm{R} \& \mathrm{D}$ activities. Looking at a sample of manufacturing firms Scherer (1991) finds that process R\&D increases relative to product R\&D as the size of the firm increases. Cohen and Klepper (1996) qualify Scherer's results. They measure process $R \& D$ as the share of process patents over the total patent effort and firm size in terms of unit sales. They find that process share increases with size but a declining rate. Our proxy for firm size is the number of employees divided by 1,000 (EMP). We expect this variable to be positively related to innovativeness and to significantly affect impact on the probability of doing process innovation when compared to product innovation. Third, we account for firm status. Concentration of R\&D activity at the firm's headquarter has been found to positively impact on innovation (Mohnen and Hoareau, 2002). HEADQ is a dummy, which is equal to 1 if the respondent was located within the central, headquarter of the company. We expect this dummy to positively affect innovation. 
Finally we control for sector fixed effect by introducing a set of industry dummies. Indeed, innovative characteristics are sector specific (Malerba, 2002) and can be assumed to derive from differences in technological characteristics (Pavitt, 1984), opportunities, and appropriability regimes (Levin et al., 1987). These variables should account for the impact on the type of innovation of organisational structure and market conditions. Descriptive statistics for the variables are reported in Table I. The correlation matrix is reported in the Appendix.

[Table I about here]

\subsection{Econometric analysis and results}

We start by tackling the 'Schmookler' and the 'Myer and Marquis' hypotheses as formulated in Section 2 above. Admittedly, to carry out this type of analysis, we should consider together both innovators and non innovators. However, the response rate from non-innovators is very low which prevents us from including these firms in the sample. We have separate information on whether firms have done product or process innovation though. In particular, 422 firms in our sample report to have done process innovation (in the most recent three year preceding the survey) while 491 have introduce a new or improved product. Most of these firms (395) have done both type of innovation. We focus on these firms which are particularly innovative. NEW PROC \& NEW PROD is a variable that equals 1 if the respondent has reported to have done both product and process innovation and 0 if it reported to have done just one type of innovation. We estimate a binary logit model. In particular we assume that for each firm $i$ there is an observable variable $y_{i}^{*}$ such that:

$$
\begin{array}{lll}
y=1 & \text { if } & y_{i}^{*}>0 \\
y=0 & \text { if } & \text { otherwise }
\end{array}
$$

where we define $y_{i}^{*}$ as

$$
y_{i}^{*}=\beta^{\prime} X_{i}+\varepsilon_{i}
$$

and $\square_{i}$ is distributed according to a function $F$ derived from the logistic cumulative: 


$$
F(x)=\frac{1}{1+\exp (-x)}
$$

Given the characteristics $X_{i}$ of firm $i$, we have:

$$
\operatorname{Pr}\left(y_{i}>j\right)=1-F\left(-\beta^{\prime} X_{i}\right)=\frac{\exp \left(\beta^{\prime} X_{i}\right)}{1+\exp \left(\beta^{\prime} X_{i}\right)}
$$

where $y$ is the dependent variable, $X$ is the vector of explanatory variables defined above and $\square$ the vector of coefficients. Table II reports the results of robust estimations.

\section{[Table II about here]}

Estimates show that the more firms interact with external partners, the more innovative they are as suggested by the positive and significant coefficient of EXT INTER. The coefficient of MKT SIZE is positive but not significant. As expected control variables are significant. The coefficient of the R\&D dummy is positive and highly significant thus suggesting that firms that do R\&D continuously have a higher probability of doing both process and product innovation. Size matters as suggested by the positive and significant coefficient of EMP, meaning that larger firms have a higher probability of doing both process and product innovation. This result still holds when we use the number of employees in R\&D only. The coefficient of HEADQT is negative and significant suggesting that divisions and/or delocalised subsidiaries seem to be more innovative than headquarters. Finally, estimates for the sectoral dummies confirm the traditional findings that the propensity to engage in both product and process is industry specific. In particular, firms in traditional industries such as Food and beverages and Chemical are less innovative than Computer equipment manufacturers. However, only the coefficient of Chemicals is significant.

Altogether these results seem to provide partial support for our hypotheses. Our findings tend to reject Hypothesis \# 1 (the 'Schmookler hypothesis') in the sense that market size does not seem to significantly impact on innovativeness. Interacting with external partners instead impacts positively and significantly on innovation, thus supporting Hypothesis \# 2 (the 'Myer 
and Marquis' hypothesis). However, this result has to be taken with caution since the set of 'external partners' include users but is not limited to them.

In order to probe further into this evidence we now turn into a deeper analysis of the determinants of innovative activity in our sample of firms. In particular, to be able to capture the different mechanisms underlying the innovative activity, we contrast the probability of carrying out different types of innovation. To carry out such analysis, we focus on the questions contained in the second part of the survey. As highlighted above, in the second part of the questionnaire firms were asked to focus on "the most economically important innovation introduced by the firm in the most recent three years". Of the 518 firms that answered this question, 210 referred to this innovation as a 'product innovation', 85 identified it as a 'process innovation' and 223 as a 'combined product / process or service innovation.

We consider firms' answer as the outcome of a choice among three alternatives: $j=0$ Combined product / process or service innovation, $j=1$ Product innovation, $j=2$ Process innovation. We model the choice with the following Multinomial Logit equation in which $X$ is the vector of covariates:

$$
\operatorname{Pr}\left(y_{i}=j\right)=\frac{e^{\beta_{j}^{\prime} X_{i}}}{\sum_{k=0}^{2} e^{\beta_{k}^{\prime} X_{i}}}
$$

which is normalised as follows (Greene, 2003: 860):

$$
\operatorname{Pr}\left(y_{i}=j\right)=\frac{e^{\beta_{j}^{\prime} X_{i}}}{1+\sum_{k=1}^{j} e^{\beta_{k}^{\prime} X_{i}}} \quad \text { for } \quad J=1,2
$$

$$
\begin{aligned}
& \text { and } \\
& \operatorname{Pr}\left(y_{i}=0\right)=\frac{1}{1+\sum_{k=1}^{j} e^{\beta_{k}^{\prime} X_{i}}}
\end{aligned}
$$

Results of the estimation are summarised in Table III below.

[Table III about here] 
The first column contrasts the choice of doing 'pure' product innovation with the choice of doing service or a combined process/process innovation. With respect to the previous results, there are some interesting differences. Indeed, CUST INTER, our proxy for the uncertainty effect, is negative and not significant. The size of the market (MKT SIZE), as measured by the number of competitors is not significant too. The coefficient for $R \& D$ is positive and significant as expected while the estimate for EMP is not significant thus suggesting that size does not seem to significantly affect the probability of doing product innovation with respect to service or combined product/process innovation. It is interesting to notice that firm status, as proxied by HEADQ, is now positive and weakly significant, thus suggesting that firms located in headquarter are more likely to do product innovation than other type of innovations. Industry dummies are all negatives and significant confirming that traditional industries such as Chemicals and Food and beverages are less innovative than high tech ones but also the presence of variety within high tech industries. In particular, some high tech industries (specifically Telecom and Computer Services) tend to do less product innovation than Communication equipment (the reference category).

In the second column we contrast the probability of doing only process innovation with the probability of doing combined product and process innovation. The remarkable results here are the coefficients of CUST INTER and MKT SIZE, which are both significant. The negative coefficient of CUST INTER suggests that firms that find interaction with customers most important for both innovation completion and innovation ideas are less likely to engage in process innovation than in other types of innovation. The positive coefficient of MKT SIZE instead suggests that firms in larger markets are more likely to do process innovation.

The last column reports the most interesting results. Here we contrast the probability of doing process innovation only with the probability of doing product innovation. In this column coefficients are the difference between those of the second and the first column. An increase in the coefficient of the explanatory variable would increase the probability of doing process innovation if the estimated coefficient for process innovation is higher than the corresponding coefficient for product innovation. In this case, results for CUST INTER and MKT SIZE confirm the previous ones. Firms that value highly the interaction with customer have a lower probability of doing process innovation while this probability is higher the larger the size of the market the firm is operating in. In this case, size matters as suggested by the positive and 
significant coefficient for EMP, which suggests that larger firms have a higher probability of carrying out process innovation than product innovation. Finally, coefficients for industry dummies are now positive though significant only in the case of Telecommunications Services suggesting that firms in this industry have a higher probability of doing process innovation than other firms in the sample. The bottom of the table reports results of two tests. The IIA (Independence of Irrelevant Alternatives) test checks whether the three alternatives considered (i.e. doing product innovation, doing process innovation, doing combined product / process innovation or service innovation) are indeed independent. Results of the test confirm the assumption that they are independent. With the combined LR test, we reject the null hypothesis that each category can be merged with the other two.

Demand might play two roles in the process of innovation. It can act as 'monetary mechanism' by providing incentives through a large market size or it can lower the uncertainty associated to with innovation outcomes. These two mechanisms have a different impact on the innovative output, because the incentive effect tends to favour process innovations, while the uncertainty effect pulls product innovations. All in all, our results suggest that if we do not account for the type of innovation, empirical evidence turns out to be weak, as shown by the first regression. To unveil the two mechanisms, we propose a model where product and process innovations are separately considered. In this case, our results strongly confirm the hypothesis that external interaction favour product innovations when contrasted with process innovation. Also, the evidence that the size of the market increases the likelihood of observing process innovation is significant albeit weakly.

Due to the complexity of the innovation process, a neat estimation of the impact of the two effects is problematic and prevents us from precisely assessing the return on innovatin from the increase in market size and/or interaction with users. However, we can conclude that, depending on which effect is prevailing, demand directs firms innovative activity towards either process or product innovation.

\section{Conclusions}

This paper, has presented an empirical analysis of the influence of demand upon product and process innovations. The existing literature on innovation generally points to two effects of demand upon innovation. On the one hand, demand offers an economic incentive to firms who want to innovate. If an improvement in the production techniques or in the product's 
quality ensured a higher mark-up per unit, the value of the future stream of profits would be the higher the greater the number of units sold. This should hold especially for process innovation or incremental product innovation where it is easy to forecast the expected size of the market. On the other hand, introducing either new products or radical product improvements and forecasting their pace of adoption is a difficult task due to the intrinsic uncertainty associated to novelty. According to this view demand can trigger innovation by reducing uncertainty (i.e. by providing useful knowledge about markets' need). By reducing firms' uncertainty about expected profits, knowledge can help firms to innovate. Empirically distinguishing between the two effects can be hard mainly for two reasons. First, it can be argued that a clear-cut distinction between the two effects is hard to observe. Both effects might be at work at the same time and they might be difficult to disentangle. Second, it should be acknowledged that these effects impinge upon firms' choices in a different way and an empirical test should consequently take this into account. This paper has attempted to provide some empirical evidence on the impact of these two effects on the likelihood to innovate.

Considering the size of the market as a proxy for the presence of demand, we found support for the idea that the presence of incentives stimulates innovation. This is particularly true for process innovation especially when it is contrasted with product innovation. Considering interaction with customers as a way to reduce uncertainty, we found that firms with a high propensity to interact with external actors are more innovative and they tend to introduce product innovations.

These results seem promising although in need of further corroboration. One aspect that needs to be developed further is the distinction between radical and incremental innovation, which the issue of uncertainty impinges upon. Indeed, one of the reasons for the lack of statistical correlation between uncertainty reduction and product innovation can be that firms in our sample mainly do incremental innovations in which uncertainty play a minor role.

Investigating this issue will be the subject of future research. 


\section{REFERENCES}

1. Adner, R., and D. Levinthal (2001). Demand heterogeneity and technology evolution: Implications for product and process innovation. Management Science, 47, 5: 611628.

2. Berger, A. J. (1975). Factors Influencing the Locus of Innovation Activity Leading to Scientific Instrument and Plastics Innovation., SM thesis, Cambridge, (Mass.): Sloan School of Management, MIT

3. Boyden, J. W. (1976). A Study of the Innovative Process in the Plastics Additives Industry. SM thesis, (Mass.): Sloan School of Management, MIT, Cambridge 1976.

4. Brouwer, E. and A. Kleinknecht (1996), Firm Size, Small Business Presence and Sales of Innovative Products: A Micro-Econometric Analysis, Small Business Economics, 8: 189-201.

5. Caloghirou, Y., Constantelou, A., Vonortas, N.S. (eds.) (2006). Knowledge Flows in European Industry: Mechanisms and Policy Implications, London: Routledge.

6. Clark, K. (1985). The interaction of design hierarchies and market concepts in technological evolution. Research Policy, 14, 235-51.

7. Cohen, W.M. and D.A. Levinthal (1990). Absorptive capacity: a new perspective of learning and innovation. Administrative Science Quarterly, 35, 128-152.

8. Cohen, W.M. and S. Klepper (1996). Firm size and the nature of innovation within industries: the case of process and product R\&D. The Review of Economics and Statistics, 232-243.

9. Cohen, W.M., Nelson, R.R., and J.P. Walsh (2002). Links and impacts: The influence of public research on industrial R\&D. Management Science, 48, 1, 1-23. 
10. Czarnitzki, D. and K. Kraft (2004). Firm Leadership and Innovative Performance:

Evidence from Seven EU Countries. Small Business Economics, 22: 325-332.

11. Dosi, G. (1982). Technological paradigms and technological trajectories: a suggested interpretation of the determinants and directions of technical change. Research Policy, 11, 3:147-62.

12. Freeman, C. (1968). Chemical Process Plant: Innovation and the World Market.. National Institute Economic Review, 45, August: 29-57.

13. Freeman, C. and L. Soete (1997), The economics of industrial innovation ( $3^{\text {rd }}$ Edition), Pinter, London.

14. Greene, W.H. (2003). Econometric Analysis. Englewood Cliffs: Prentice Hall.

15. Herstatt, C., and E. von Hippel (1992). From Experience: Developing New Product Concepts Via the Lead User Method: A Case Study in Low Tech Field. Journal of Product Innovation Management, 9:23-221.

16. Isenson, R. S. (1969). Project Hindsight: An Empirical Study of the Sources of Ideas Utilized in Operational Weapon Systems. In Gruber, W.H. and G. Marquis (eds.) Factors in the Transfer of Technology, Cambridge, Mass.: MIT Press.

17. Kleinknecht, A. and B. Verspagen (1990). Demand and innovation: Schmookler reexamined. Research Policy, 19, 4: 387-394.

18. Langrish, J., Gibbons M., Evans W.G., and F.R. Jevons (1972). Wealth from knowledge: A study of innovation in industry. New York: John Wiley.

19. Laursen, K. A. Salter (2006). Open for innovation: the role of openness in explaining innovation performance among UK manufacturing firms, Strategic Management Journal, 27, 2: 131-150. 
20. Levin, R., Klevorick, A., Nelson, R.R. and S.G. Winter (1987). Appropriating the returns from industrial R\&D. Brookings Papers on Economic Activity, 820.

21. Lichtenberg, F., and J. Waldfogel (2003). Does Misery Love Company? Evidence from pharmaceutical markets before and after the Orphan Drug Act, NBER Working Paper No. 9750 .

22. Link, A. N. (1982). A Disaggregated Analysis of Industrial R\&D: Product versus Process Innovation. In D. Sahal (ed.) The Transfer and Utilization of Technical Knowledge: Lexington Books, Lexington, MA.

23. Lionetta, W. (1977). Sources of Innovation Within the Pultrusion Industry. Unpublished S.M. thesis, Sloan School of Management, Cambridge, (Mass.): Massachusetts Institute of Technology.

24. Malerba, F. (2002). Sectoral systems of innovation and production. Research Policy, 31, 247-264.

25. Malerba, F., Nelson, R.R., Orsenigo, L., and S.G. Winter (2003). Demand, innovation and the dynamics of market structure: the role of experimental users and diverse preferences. WP CESPRI n. 135, Università Luigi Bocconi, Gennaio 2003.

26. Mohen, P. and Hoareau, C. (2003), What type of enterprises forges close links with universities and government labs? Evidence from CIS 2. Managerial and Decision Economics, 24, 133-145.

27. Morrison, P. D., Roberts, J.H., and E. von Hippel (2000). Determinants of User Innovation and Innovation Sharing in a Local Market. Management Science, 46, 12: 1513-1527.

28. Mowery, D.C., and N. Rosenberg (1979). The Influence of Market Demand upon Innovation: a Critical Review of some Recent Empirical Studies. Research Policy, 8: 102-53. 
29. Myers, S., and D.G. Marquis (1969). Successful Industrial Innovation, Washington: National Science Foundation.

30. National Science Foundation (1959), Report on Project TRACES Washington

31. Pavitt, K. (1984), Patterns of technical change: towards a taxonomy and a theory, Research Policy, 11, 1: 33-51.

32. Pavitt, K. ,Robson M. and J. Towsend (1987), The size distribution of innovating firms in the UK: 1945-1983, Journal of Industrial Economics, 35, 291-316.

33. Popp, D. (2002) "Induced Innovation and Energy Prices" American Economic Review, 92: $160-180$.

34. Reinganum, J. (1989), “The timing of Innovation: Research, Development and Diffusion”, in Handbook of Industrial Organization, Vol. I, ed. by R. Schmalensee and R.Willig. Amsterdam: North-Holland.

35. Rothwell, R., and C. Freeman (1974). SAPPHO Updated - Project SAPPHO Phase II, Research Policy, 3: 258-91.

36. Scherer, F. (1982). Demand Pull and Technological Invention: Schmookler Revisited. Journal of Industrial Economics, 30, 225-37.

37. Scherer, F. (1991), Changing perspectives on the firms size problem. In Z.J. Acs and D.B. Audretsch (eds.) Innovation and technological change. An international comparison. Harvester Wheatsheaf, New York.

38. Schmookler, J. (1962) Economic Sources of Inventive Activity. Journal of Economic History 22,1: 1-20.

39. Schmookler, J. (1966) Invention and Economic Growth, Cambridge, MA: Harvard University Press. 
40. Sutton, J. (1998). Technology and Market Structure: Theory and History. Cambridge (MA): MIT Press.

41. Teubal, M. (1979). On User Needs and Need Determination: Aspects of the theory of Technological Innovation. In M. Baker (ed.) Industrial Innovation: Technology, Policy, Diffusion, London: MacMillan.

42. von Hippel, Eric (1982) Appropriability of innovation benefit as a predictor of the source of innovation, Research Policy 11, 95-115.

43. von Hippel, E. (1978). Successful industrial products from customer ideas. Journal of Marketing, 42, 1: 39-49.

44. von Hippel, E. (1986). Lead Users: A Source of Novel Product Concepts. Management Science, 32: 791-805.

45. von Tunzelmann, N., and Q. Wang (2003). An Evolutionary View of Dynamic Capabilities, Economie Appliquиeе, LVI, 3: 33-64. 


\section{LIST OF TABLES}

TABLE I

SUMMARY DESCRIPTIVE STATISTICS

\begin{tabular}{lccccc}
\hline \multicolumn{1}{c}{ Variable Name } & Obs. & Mean & S.D. & Min & Max \\
\hline New Proc \& New Prod & 498 & 0.79 & 0.40 & $0: 103$ & $1: 395$ \\
Most Important Inn. & 518 & 0.73 & 0.72 & 0 & 2 \\
Ext Inter (\%) & 453 & 0.16 & 0.19 & 0 & 1 \\
Mkt Size (log) & 486 & 2.52 & 1.29 & 0 & 8.52 \\
Cust Inter & 518 & 0.45 & 0.50 & $0: 285$ & $1: 233$ \\
Emp (000s) & 518 & 0.19 & 0.26 & 0 & 1.20 \\
R\&D & 518 & 0.88 & 0.32 & $0: 62$ & $1: 456$ \\
Headq & 515 & 0.56 & 0.50 & $0: 226$ & $1: 289$ \\
Food and beverages & 518 & 0.23 & 0.42 & $0: 398$ & $1: 120$ \\
Chemicals & 518 & 0.23 & 0.42 & $0: 396$ & $1: 122$ \\
Comm. Equipment & 518 & 0.18 & 0.38 & $0: 426$ & $1: 92$ \\
Telecomm. Services & 518 & 0.09 & 0.28 & $0: 473$ & $1: 45$ \\
Computer Services & 518 & 0.27 & 0.44 & $0: 379$ & $1: 139$ \\
\hline
\end{tabular}

For dummy variables, the last two columns report the number of cases in which the variables take the value 0 or 1. 
TABLE II - DETERMINANTS OF INNOVATIVE ACTIVITY: LOGISTIC REGRESSION DEPENDENT VARIABLE: NEW PROC \& NEW PROD

\begin{tabular}{lc}
\hline & Dependent Variable \\
\hline Independent Variable & New Proc \& New Prod \\
\hline Ext Inter & 1.949 \\
Mkt Size & {$[0.804]^{* *}$} \\
R\&D & 0.076 \\
& {$[0.112]$} \\
EMP & 1.304 \\
& {$[0.350]^{* * *}$} \\
Headq & 2.074 \\
& {$[0.922]^{* *}$} \\
Industry Dummies & -0.618 \\
Food and Beverages & {$[0.274]^{* *}$} \\
& \\
Chemicals & -0.577 \\
& {$[0.444]$} \\
Telecomm. Services & -0.922 \\
& {$[0.433]^{* *}$} \\
Computer Services & 0.498 \\
& {$[0.639]$} \\
Constant & -0.608 \\
& {$[0.417]$} \\
Observations & 0.385 \\
Log Pseudo LL & {$[0.608]$} \\
Wald Chisq & 427 \\
Pseudo Rsq & -196.098 \\
$*$ denotes 10\% significance level, ** denotes 5\% significance level, *** denotes 1\% significance level. \\
Robust standard errors in brackets & 0.103 \\
a Reference class: Communication Equipment & \\
\end{tabular}


TABLE III - COMPARING INNOVATION TYPES CHOICES: MULTINOMIAL LOGIT REGRESSION DEPENDENT VARIABLE: MOST IMPORTANT INNOVATION

\begin{tabular}{|c|c|c|c|}
\hline & [1 vs. 0$]$ & [2 vs. 0] & [2 vs. 1] \\
\hline Cust Inter & $\begin{array}{l}-0.038 \\
{[0.207]}\end{array}$ & $\begin{array}{c}-0.786 \\
{[0.288]^{* * *}}\end{array}$ & $\begin{array}{c}-0.748 \\
{[0.292] * *}\end{array}$ \\
\hline Mkt Size & $\begin{array}{l}-0.028 \\
{[0.083]}\end{array}$ & $\begin{array}{c}0.159 \\
{[0.098]^{*}}\end{array}$ & $\begin{array}{c}0.187 \\
{[0.099]^{*}}\end{array}$ \\
\hline R\&D & $\begin{array}{c}0.893 \\
{[0.338]^{* * *}}\end{array}$ & $\begin{array}{c}0.243 \\
{[0.417]}\end{array}$ & $\begin{array}{l}-0.650 \\
{[0.457]}\end{array}$ \\
\hline EMP & $\begin{array}{l}-0.560 \\
{[0.413]}\end{array}$ & $\begin{array}{c}0.481 \\
{[0.463]}\end{array}$ & $\begin{array}{c}1.041 \\
{[0.496]^{* *}}\end{array}$ \\
\hline Headq & $\begin{array}{c}0.386 \\
{[0.212]^{*}}\end{array}$ & $\begin{array}{c}0.296 \\
{[0.279]}\end{array}$ & $\begin{array}{l}-0.090 \\
{[0.283]}\end{array}$ \\
\hline Industry Dummies $^{\mathrm{a}}$ & & & \\
\hline Food and Beverages & $\begin{array}{c}-0.945 \\
{[0.334]^{* * *}}\end{array}$ & $\begin{array}{l}-0.715 \\
{[0.453]}\end{array}$ & $\begin{array}{c}0.229 \\
{[0.431]}\end{array}$ \\
\hline Chemicals & $\begin{array}{c}-0.809 \\
{[0.337]^{* *}}\end{array}$ & $\begin{array}{l}-0.435 \\
{[0.445]}\end{array}$ & $\begin{array}{c}0.374 \\
{[0.419]}\end{array}$ \\
\hline Telecomm. Services & $\begin{array}{c}-1.381 \\
{[0.459]^{* * *}}\end{array}$ & $\begin{array}{l}-0.303 \\
{[0.539]}\end{array}$ & $\begin{array}{c}1.078 \\
{[0.556]^{*}}\end{array}$ \\
\hline Computer Services & $\begin{array}{c}-0.912 \\
{[0.323]^{* * *}}\end{array}$ & $\begin{array}{l}-0.669 \\
{[0.438]}\end{array}$ & $\begin{array}{c}0.243 \\
{[0.412]}\end{array}$ \\
\hline Constant & $\begin{array}{l}-0.083 \\
{[0.471]} \\
\end{array}$ & $\begin{array}{c}-1.074 \\
{[0.590]^{*}}\end{array}$ & $\begin{array}{c}-0.991 \\
{[0.602]^{*}}\end{array}$ \\
\hline Observations & 483 & & \\
\hline LR Chisq (18) & $45.84 * * *$ & & \\
\hline Pseudo Rsq & 0.046 & & \\
\hline Log Pseudo LL & -472.224 & & \\
\hline IIA & 0.555 & -0.467 & \\
\hline Combined & $24.768 * * *$ & $17.222 * *$ & $20.309 * *$ \\
\hline
\end{tabular}


LIST OF FIGURES

FIGURE I - CUSTOMER INTERACTION MOST IMPORTANT BY INNOVATION TYPE AND SECTOR

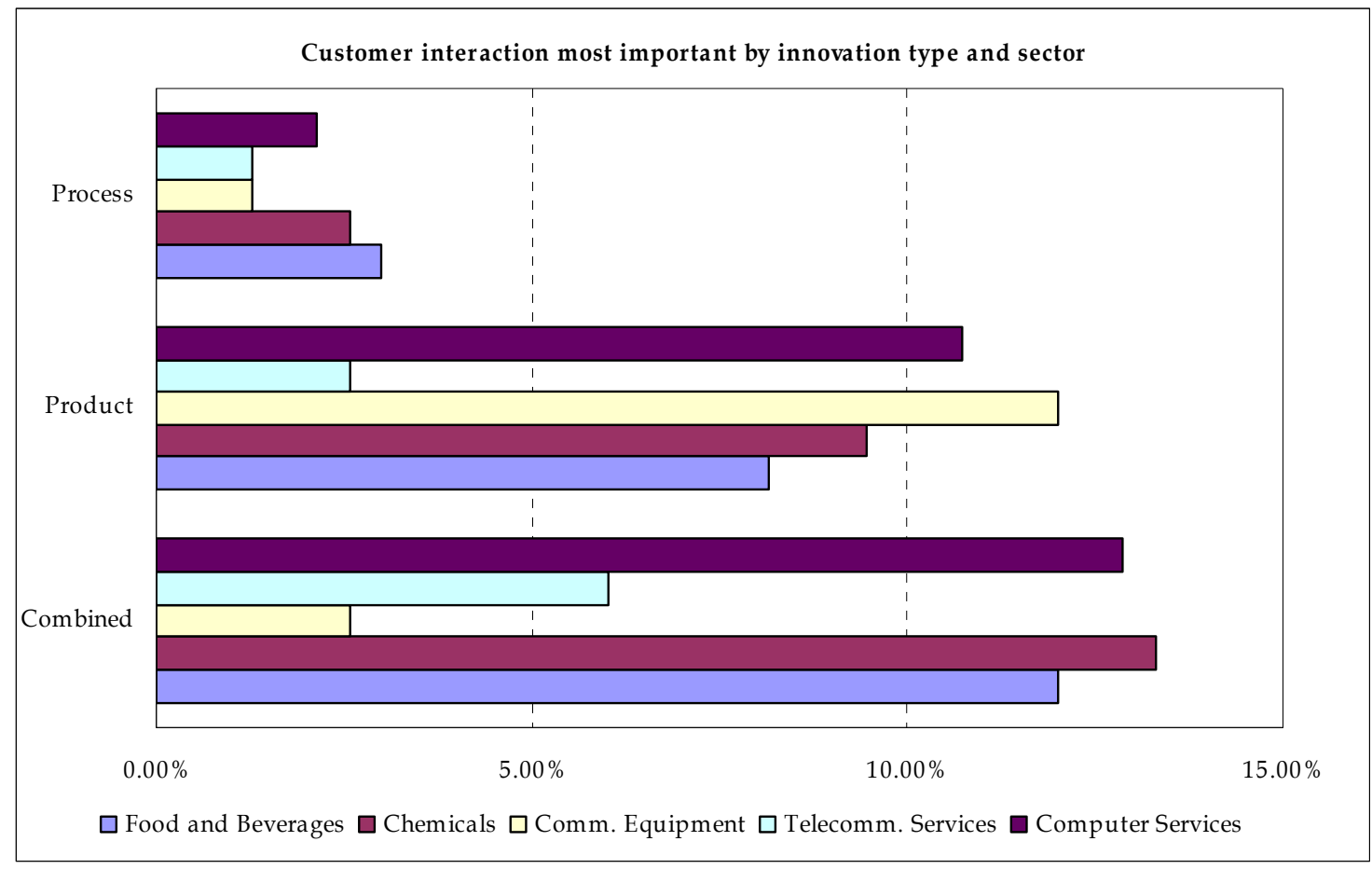


FIGURE II - MOST IMPORTANT INNOVATION BY MARKET SIZE

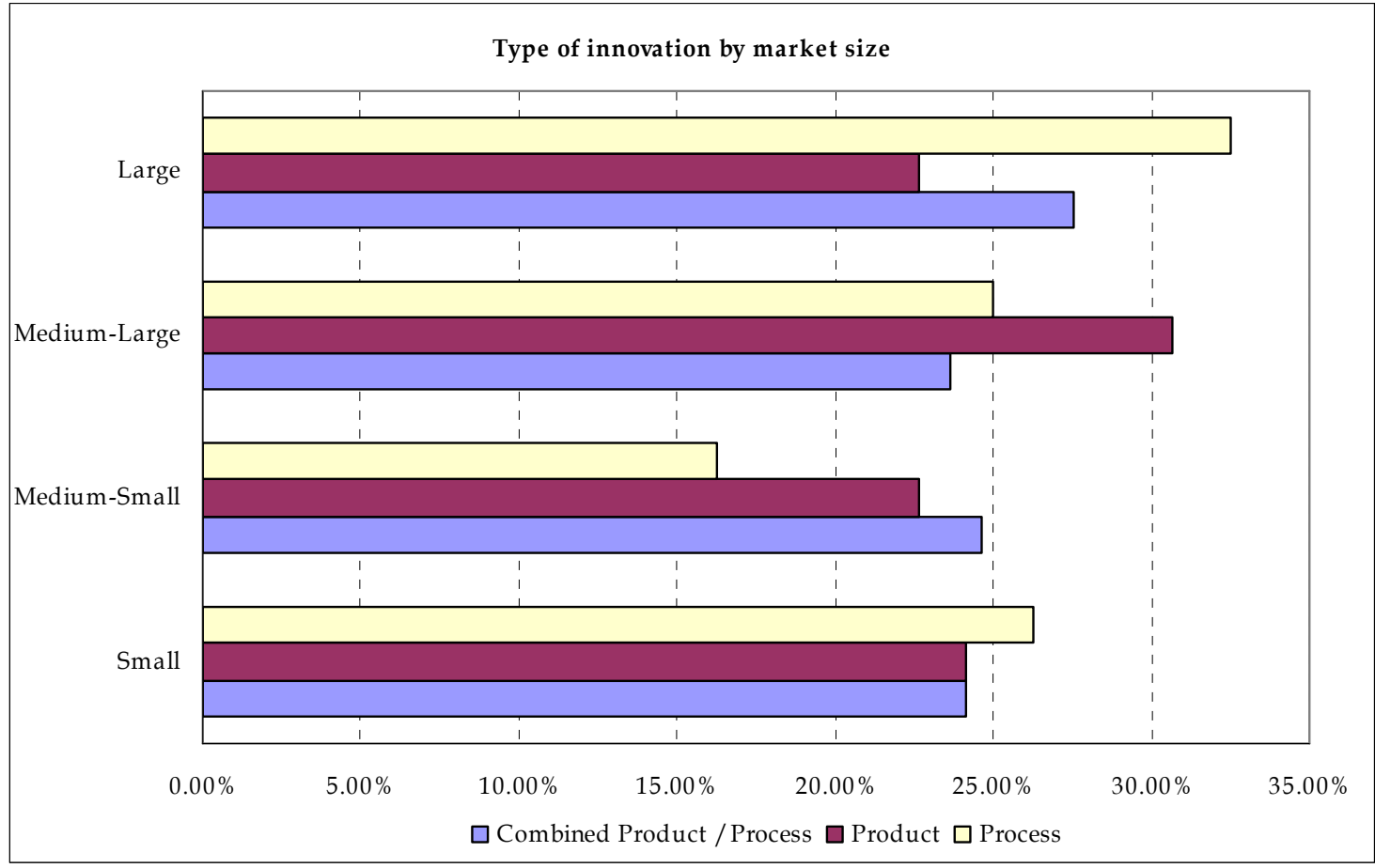


FIGURE III - MARKET SiZE FOR PROCESS INNOVATION BY SECTOR

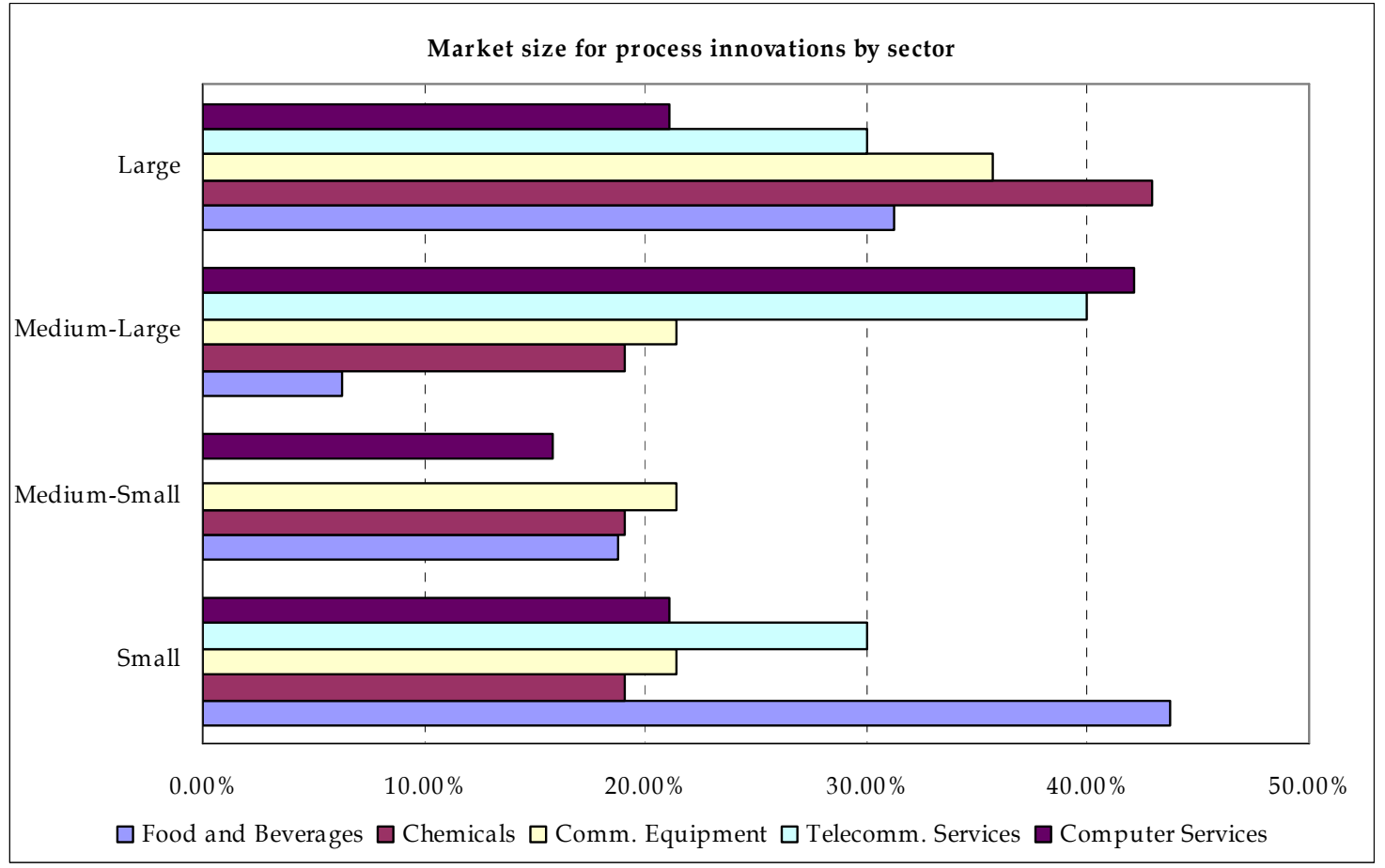


APPENDIX

TABLE A1. CORRELATION MATRIX

\begin{tabular}{|c|c|c|c|c|c|c|c|c|c|c|c|c|c|}
\hline & 1 & 2 & 3 & 4 & 5 & 6 & 7 & 8 & 9 & 10 & 11 & 12 & 13 \\
\hline 1 & 1 & & & & & & & & & & & & \\
\hline 2 & -0.068 & 1 & & & & & & & & & & & \\
\hline 3 & 0.118 & -0.085 & 1 & & & & & & & & & & \\
\hline 4 & 0.006 & 0.071 & 0.023 & 1 & & & & & & & & & \\
\hline 5 & 0.002 & -0.123 & -0.064 & -0.057 & 1 & & & & & & & & \\
\hline 6 & 0.144 & 0.051 & -0.034 & 0.055 & -0.039 & 1 & & & & & & & \\
\hline 7 & 0.161 & 0.086 & -0.022 & 0.062 & -0.049 & 0.046 & 1 & & & & & & \\
\hline 8 & -0.092 & 0.073 & -0.05 & 0.06 & 0.042 & 0.049 & -0.039 & 1 & & & & & \\
\hline 9 & -0.047 & -0.051 & 0.052 & -0.033 & 0.0002 & 0.0003 & -0.094 & -0.017 & 1 & & & & \\
\hline 10 & -0.016 & -0.003 & -0.086 & 0.101 & 0.038 & 0.087 & -0.048 & -0.119 & -0.305 & 1 & & & \\
\hline 11 & 0.031 & 0.101 & -0.011 & -0.046 & -0.044 & -0.059 & 0.062 & 0.096 & -0.255 & -0.258 & 1 & & \\
\hline 12 & 0.033 & 0.0001 & 0.101 & -0.023 & 0.038 & 0.042 & 0.05 & -0.08 & -0.169 & -0.171 & -0.143 & 1 & \\
\hline 13 & 0.012 & -0.036 & -0.019 & -0.012 & -0.022 & -0.060 & 0.049 & 0.097 & -0.333 & -0.336 & -0.281 & -0.187 & 1 \\
\hline
\end{tabular}

9. FoOd AND BEVERAGES; 10. ChemiCAls; 11. COMM EQuiPMENT; 12. TELECOMM. SERVICES; 13. COMPUTER SERVICES. 


\section{FOOTNOTES}

${ }^{1}$ Usual assumptions hold: $F(-\infty)=0, F(\infty)=1$, and $f\left(\Pi_{t}\right)=\frac{\partial F\left(\Pi_{t}\right)}{\partial \Pi_{t}}>0$

${ }^{2}$ This holds, taking into account the following important caveat. Process innovation can be considered a good proxy for the result of an incentive-led innovation process, while product innovation may be only weakly linked to the presence of the uncertainty effect.

${ }^{3}$ The KNOW survey was undertaken during a research project funded by the European Commission. Carried out in 2000 by means of Computer Aided Telephone Interviews (CATI) method, it actually refers to 1999. See Caloghirou et al. (2006), for the description of the survey's methodology and main results.

${ }^{4}$ In both cases the exact wording of the question(s) was: "What percentage of your firm's new or improved production processes (products) were introduced using any of the following methods: Buying-in; In-house development; Collaboration with external partners."

${ }^{5}$ Information on the amount of R\&D expenditure is available. It has not been included in the regression due to correlation with firm size. 